\title{
LATITUDINAL GRADIENT IN THE PLASMA BUBBLE ZONAL VELOCITIES AS OBSERVED BY SCANNING 630-nm AIRGLOW MEASUREMENTS
}

\author{
J.H.A. Sobral and M.A. Abdu
}

Instituto de Pesquisas Espaclais, São Josẽ dos Campos, São Paulo, Braz11

\begin{abstract}
Equatorlal Ionospheric plasma bubble zonal velocities were measured using two 630-nm scanning photometers. Simultaneous scanning measurements were made in two east-west planes that were tilted $30^{\circ}$ northward and southward of the vertical. The results of measurements carrled out during 5 days covering the sumer equinoctial perfod of 1988, presented here, show evidence of marked latitudinal gradient in the bubble zonal velocities, the velocities decreasing with increasing latitude over our low-latitude observing site, Cachoeira Paulista $\left(-28^{\circ} \mathrm{dip}\right)$. We suggest that this velocity gradient is consistent with expectations at solar minimum, when our measurements may be associated with the region above the maximum in the eastward plasma velocity height profile.
\end{abstract}

\section{Introduction}

The nighttime equatortal Ionospheric plasma motion is controlled mainly by the $F$ region dynamo-induced electric field driven by the zonal component of the neutral wind which blows eastward from evening to early morning hours [RIshbeth, 1971; S1pler and Blond1, 1978; Wharton et al., 1984; Fejer et al., 1985]. This electric field also serves as a primary driving force in the generation of the $F$ region irregularities that are often characterized by the presence of flux tube aligned transequatorlal plasma bubbles, or plasma depletions [McClure et al, 1977; Tsunoda, 1980]. Since the bubbles drift zonally with velocities of ten comparable with that of the ambient plasma, they can, under proper conditions, be used as tracers of the ambient plasma motion. The bubble-induced depletions in the $630-\mathrm{nm}$ airglow intensities, as recorded in the E-W profile of this emission observed by scanning photometers, have been analyzed to determine the zonal propagation characteristics of these bubbles over the Brazillan low-latitude location Cachoefra Paulista [see Sobral et al., 1985; Abdu et al., 1987].

Plasma bubble zonal velocity characteristics over Cachoefra Paulista have also been studied using the bubble-induced total electron density depletion signatures as measured by VHF electronic polarimeters operated in east-west spaced mode [Abdu et al., 1985, 1987]. These results over low latitude, when assessed in the light of the ambient plasma zonal velocities over the equator as measured by the Jicamarca radar [Fejer et a1., 1985] and also with Fabry-Perot zonal neutral wind measured over near equatorial

Copyright 1990 by the American Geophysical Union.

Paper number 89JA03519.

0148-0227/90/89JA-03519\$02.00 statlons Rwajalein and Natal e.g., Sipler and Blond1, 1978], would seem to suggest the possible existence of a latitudinal varlation in the zonal velocities, whether referred to neutral wind, amblent plasma, or plasma bubble motions. Intercomparisons of the existing data, which are diverse and nonsimultaneous, are not, however, helpful to draw any conclusion regarding such a possibility. In this context an attempt is made here, from observations using an east-west scaninng 630-nm photometer set-up, to determine the existence or otherwise of latitude-dependent east-west plasma bubble velocities.

The results to be discussed here were obtalned using an experimental set-up consisting of two east-west scanning photometers whose scanning planes were tilted $30^{\circ}$ toward north and south of the vertical. The photometer viewing angle (cones of $5^{\circ}$ each) projections, at a reference altitude of $300 \mathrm{~km}$, north and south of the vertical, are shown in Figure 1. Each photometer scan covers $75^{\circ}$ of elevation angle centered around the vertical.

\section{Results}

The results to be presented and discussed here correspond to five nights of observations during the months of January and March 1988 (see Table 1). For these nights the data were of excellent quality in the sense that the signal-to-noise ratio of the emission was high, with clearly defined depletion valleys being present in the zonal intensity profiles. Some examples of eastward propagating valleys have been presented before by sobral et a1. [ 1980, 1985]. Figure 2 shows plots of the 630-nm intensity zonal profiles corresponding to the two scanning planes, namely, $30^{\circ} \mathrm{N}$ and $30^{\circ} \mathrm{S}$, obtalned on one of the nights (January 17), during the present set of . observations. We11-defined eastward propagating airglow depletion valleys are clearly seen in both scanning planes. The dashed lines that follow the propagation of the valleys in this figure will be referred to, from here on, as alrglow depletion "tracks". Such tracks were used to calculate the eastward velocities $\left(V_{E}\right)$. $V_{E}$ values calculated on January 17, using the three tracks (that are shown in Figure 2), and 20 minute data samples, namely, 2020-2040, 20402100, and 2100-2120 LT are presented In Figure 3, wherein the variances in the velocities are shown as vertical bars. No clear local time trend in $V_{F}$ is evident. The velocities in the northern scanning plane are clearly higher than those in the southern plane, since the mean of the former velocities is higher than that of the latter velocities by a factor of up to 38 percent. In Table 1 we have presented numerical values of $V$ in the scanning planes $30^{\circ} \mathrm{N}$ and $30^{\circ} \mathrm{S}$ of zenith for a total of 10 tracks corresponding to the 


\section{PHOTOMETER VEWNG ZONES AT THE ALTTIDE OF $300 \mathrm{~km}$}

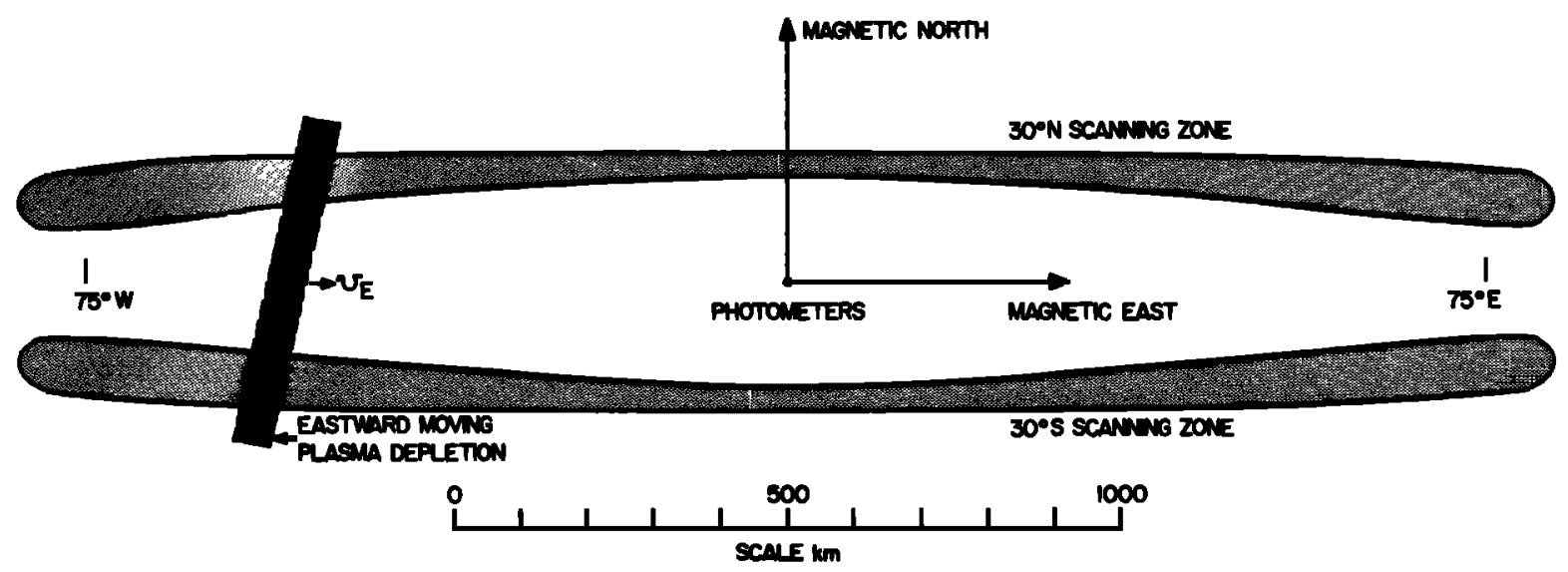

F1g. 1. East-west scan projection at $300 \mathrm{~km}$ height of the photometer viewing angles (cones of $5^{\circ}$ each) at $30^{\circ}$ north and south of vertical.

five nights of observation presently under consideration. The largest differences between the two sets of velocities occurred on the nights of January 17-18 and of March 22-23, 1988, the northern velocities belng higher by a factor over 38 percent. A plot of all these velocities, in northern versus southern format, is shown in Figure 4, which clearly demonstrates a tendency for northward velocities to exceed the southward velocities. The difference between the two seems to Increase for higher values of the velocities.

\section{Discussion and Conclusions}

The merldional distance, at $300 \mathrm{~km}$ reference altitude, of the north and south photometer sensing regions $1 \mathrm{~s}$ around $340 \mathrm{~km}$. The helght of the airglow emission layer, nominally situated

Table 1. East-West A1rglow Depletion Velocities observed With Photometer Scanning in the Northern and Southern Planes

\begin{tabular}{lcc}
\hline & \multicolumn{2}{c}{ Velocity, ms } \\
\cline { 2 - 3 } Date, 1988 & VE $\left(30^{\circ} \mathrm{N}\right)$ & $\mathrm{VE}\left(30^{\circ} \mathrm{S}\right)$ \\
\hline Jan. 17-18 & 180 & 167 \\
& 176 & 133 \\
Jan. 19-20 & 188 & 136 \\
& 35 & 36 \\
March 11-12 & 22 & 26 \\
March 13-14 & 90 & 72 \\
& 124 & 101 \\
March 22-23 & 106 & 106 \\
& 63 & 58 \\
\hline
\end{tabular}

Data are for 10 airglow depletion tracks (see the text) on the five nights of observations discussed in the text. approximately one scale helght below the $F$ peak, is not expected to vary significantly within such a latitudinal distance. The systematically different plasma bubble zonal velocities obtained from the northward and southward looking photometers therefore represent essentially a latitude variation in the velocities, decreasing from north to south.

If we consider the flux tube alignment characteristics of the transequatorial plasma bubble structures [Tsunoda, 1980; Weber et al., 1978; Tinsley, 1982; Abdu et al., 1983], the negative latitude gradient feature of the $v_{F}$ observed in the present measurement will correspond to a negative height gradient of the eastward velocities above the magnetic equator. This negative gradient would be present within a height range from approximately $590 \mathrm{~km}$ to $760 \mathrm{~km}$, which represents the apex of the field lines passing, respectively, through the north and south photometer scanning zones over Cachoelra Paulista.

From simplified theoretical considerations, and using flux tube integrated electron densities and collision frequencles, Anderson and Mend11lo [1983] have calculated integrated Pederson conductivity and eastward ExB plasma drift $\left(V_{\mathrm{E}}\right)$ vertical profiles over the equator. The Integrated conductivity in their model (their Figure 4) Increases rapidly up to a height of approximately $550 \mathrm{~km}$ and less rapidly above this height, the turnover height depending upon the flux tube integrated electron density peak height. The height profile of their eastward plasma velocities above the $550-\mathrm{km}$ level, however, depends also upon the precise latitudinal varlation in the zonal neutral wind in such a way that their model yielded a negative helght gradient of $V_{E}$ at helghts above $550 \mathrm{~km}$ for a latitudinally decreasing (negative gradient) wind function; the $V_{E}$ height gradient was positive when a latitude independent neutral wind was assumed. We might recall also, as mentioned earlier and by Abdu et al. [1987], that the zonal plasma bubble veloctty measured over low-latitude sites would approach very closely that of the ambient plasma. 


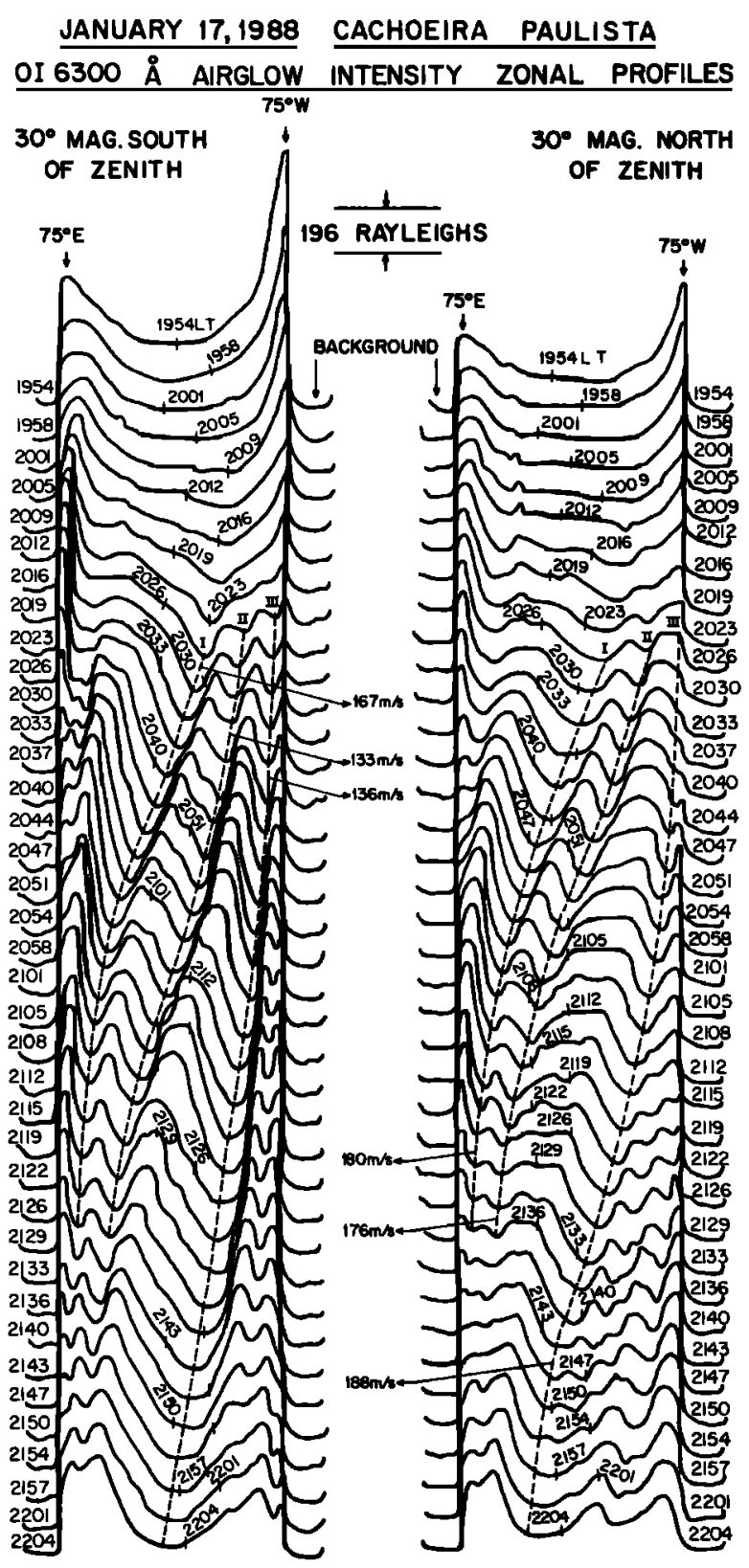

F1g. 2. The 630-nm airglow intensity zona1 profiles corresponding to the two scanning planes $30^{\circ} \mathrm{N}$ and $30^{\circ} \mathrm{S}$ of vertical obtalned on the night of January $17,1988$.

On the basis of the above considerations our observations of a latitudinally decreasing plasma bubble zonal velocity could Imply the existence of a latitudinally decreasing neutral zonal wind over our low-latitude site.

In a recent study, Abdu et a1. [1987] compared the bubble zonal velocities obtained from simultanous measurements by spaced VHF polarimeters and a scanning 630- $\mathrm{nm}$ photometer over Cachoelra Paullsta. They found that the eastward bubble velocity presented a positive helght gradient, namely, latitude gradient, over Cachoeira Paulista which Indicated a positive

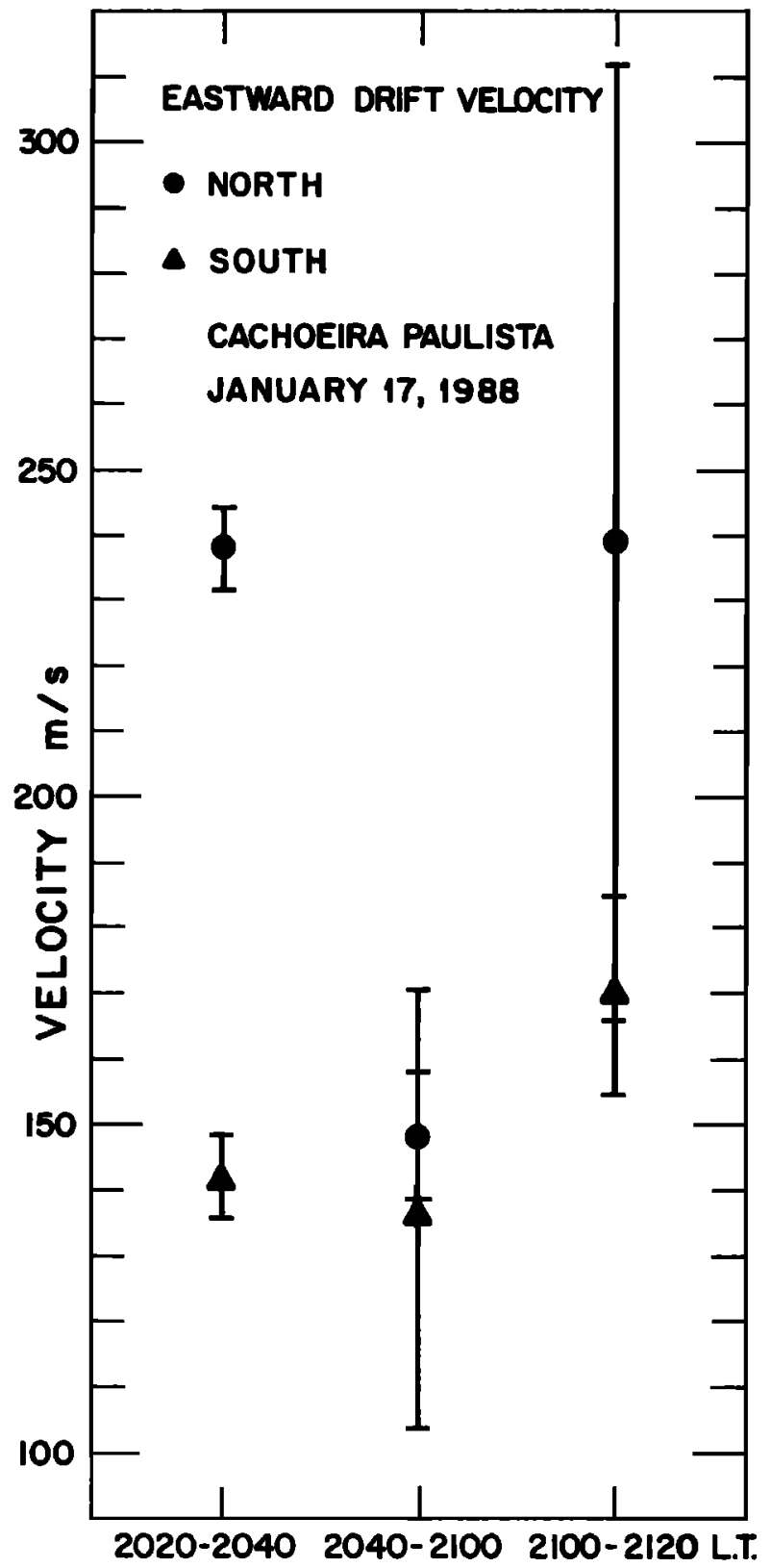

Fig. 3. Eastward velocities of the alrglow depletions determined for the data in Figure 3 as explained in the text. The vertical bars represent the variance in the velocities.

helght gradient over the equator. These results might appear to be at varlance with the present observation of a negative latitude gradient over the same location. This apparent discrepancy could be explatned as follows. As shown by Anderson and Mendi11o [1983], the sense of the eastward velocity height gradient over the equator would depend upon the preclse nature of the latitude variation in neutral zonal wind. Thus it could be argued that the neutral wind latitude gradient was positive during the measurements reported by $A b d u$ et al. [1987], whereas it has turned negative during the present 


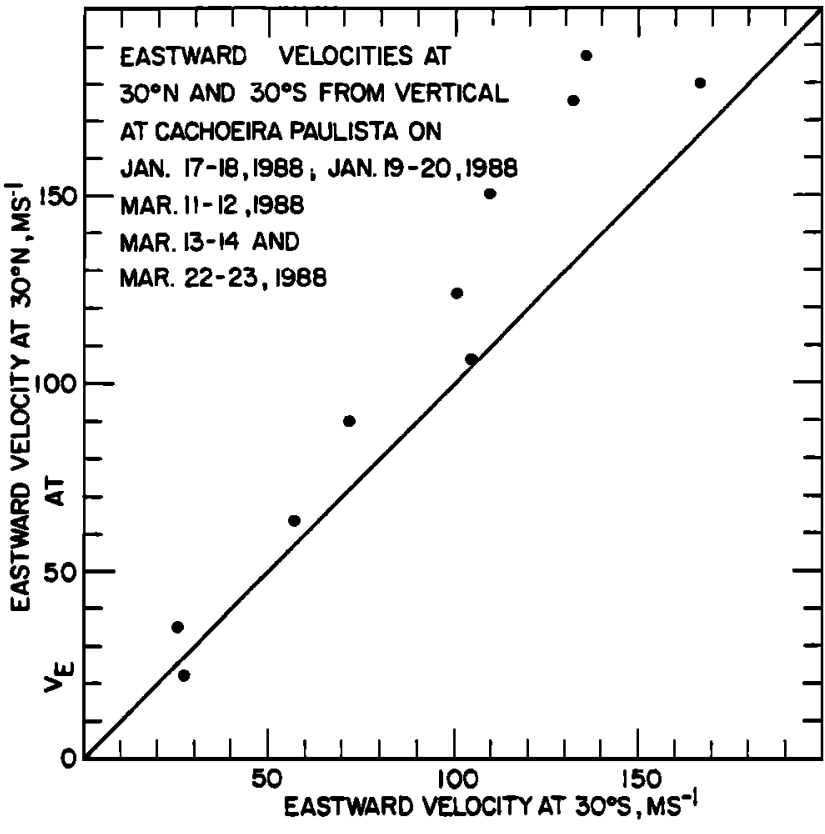

Fig. 4. Zonal velocitieg of the airglow depletions observed northward of the station are plotted against those observed southward, on the five nights of observation.

measurements. While such changes in the neutral wind latitude distribution could be concelvable, we do not find it entirely convincing that a reversal in the wind gradient could have taken place between the two epochs of measurements.

A more likely explanation, we belleve, could be found in the nature of the $F$ peak height varfations. The measurement of Abdu et al. [1987] were taken during the 1981-1983 period, which was close to the solar activity maximum epoch, whereas the present measurements represent conditions closer to the solar activity minimum. The nighttime $F$ peak helght undergoes substantial decrease (especially over the equator) from solar maximum to minimum, since it is controlled mainly by the $F$ region dynamo electric field and the assoclated evening prereversal enhancement in the $F$ region ionization vertical drift velocities, whose positive dependence on solar activity has been demonstrated from Jicamarca radar measurements by Fejer et al. [1979]. These variations in the $F$ peak height could, in turn, shift downward or upward the $V_{E}$ and conductivity profiles such as those calculated by Anderson and Mendillo [1983]. Therefore the following scenarto could be consldered. The F layer fleld lines over Cachoeira Paulista corresponding to the photometer scanning zones in the present measurements could be mapped onto the negative gradient (or "topside") region of the $V_{E}$ vertical profile over the equator (as mentioned earlier). During the previous measurement (representing a higher mean solar activity level) by Abdu et al. [1987] the higher altitude of fleld line Integrated Nmax could shift the turnover point (or peak) of the $V_{E}$ helght profile to relatively higher levels. As a result, the F region field line corresponding to the polarfmeter and photometer measurements over Cachoelra Paulista could be mapped onto the positive gradient region (or bottomside) of the $\mathrm{v}_{\mathrm{E}}$ height profile.

In conclusion, the plasma bubble zonal velocities, as measured by east-west scanning 630-nm photometers, show clear evidence of a latitude gradient, which, in the present measurement, shows up as the eastward velocities increasing equatorward from our low-latitude observing site. From pub1lshed models based on simplified theoretical considerations it appears that such velocity gradients could be produced by a similar latitude gradient in the zonal neutral wind and/or by a downward shift (with decreasing solar activity) of the integrated Pederson conductivity height profile in the equatorial plane.

Acknowledgments. This work has been partially supported by the Fundaçāo de Amparo $\bar{a}$ Pesquisa do Estado de Sào Paulo (FAPESP grant 87/3585-3) and by the Conselho Nactonal de Desenvolvimento Cientifico e Tecnológico (CNPq grant 300669-89.5). The authors are grateful to P. Muralikrishna for his useful suggestions and also to Pedro Paulo and Hello Borges who have helped to run the present experiments.

The Editor thanks two referees for their assistance in evaluating this paper.

\section{References}

Abdu, M.A., R.T. Medeiros, and Y. Nakamura, Latidudinal and magnetic flux tube extenston of the equatorlal spread $F$ irregularities, $J$. Geophys. Res., 88, 4861-4868, 1983.

Abdu, M.A., I.J. Kantor, I.S. Bat1sta, and E.R. de Paula, East-west plasma bubble Irregularity motion determined from spaced VHF polarimeters: Implications on velocity shear in the zonal F-region bulk plasma motion, Radio Sctence, 20, 111-122, 1985.

Abdu, M.A., J.H.A. Sobral, Y. Nakamura, and C.J. Zamlutt1, Equatorial plasma bubble zonal velocity height gradient from spaced VHF polarimeter and scanning $630-\mathrm{nm}$ measurements, Geophys. Res. Lett., 14, 965-968, 1987.

Anderson, D.N., and M. Mendillo, Ionospheric conditions affecting the evolution of equatorial plasma depletions, Geophys. Res. Lett., 10, 541-544, 1983.

Fejer, B.G., D.T. Farley, R.F. Woodman, and C. Calderon, Dependence of equatorial $F$ region vertical drifts on season and solar cycle, J. Geophys. Res., 84, 5792-5796, 1979.

Fejer, B.G., E. Kudek1, and D.T. Farley, Equatorial F region zonal plasma drifts, J. Geophys. Res., 90, 12,249-12,255, 1985.

Mcclure, J.P., W. B. Hanson, and J.H. Hoffman, Plasma bubbles and Irregularities in the equatorial lonosphere, J. Geophys. Res., 82, 2650-2656, 1977

Rishbeth, H., The F-region dynamo, Planet. Space Sci., 19, 263-267, 1971.

Sipler, D.P., and M.A. Biondi, Equatorlal neutral wind from alrglow 0I630 nm Doppler shifts, Geophys. Res. Lett., 5, 373-376, 1978. 
Sobra1, J.H.A., M.A. Abdu, I.S. Batista, and C.J. Zamlutt1, Assoclation between plasma bubble irregularities and airglow disturbances over Brazt1ian low latitudes, Geophys. Res. Lett., 7, 980-982, 1980.

Sobral, J.H.A., M.A. Abdu, and Y. Saha1, Equatorial plasma bubble eastward velocity characteristics from scanning alrglow photometer measurements over Cachoelra Paullsta, J. Atmos. Terr. Phys., 47, 895-900, 1985.

Tinsley, B.A., Field aligned-airglow observation of transequatorial bubbles in the tropical Fregion, J. Atmos. Terr. Phys., 44, 547-557, 1982.

Tsunoda, R.T., Magnetic - fleld - aligned characteristcs of plasma bubbles in the nighttime equatorial lonosphere, J. Atmos. Terr. Phys., 42, 743-752, 1980.
Weber, E.J., J. Buchau, R.H. Eather, and S.B. Mende, North-gouth aligned equatorlal alrglow deplettons, J. Geophys. Res., 83, 712-716, 1978.

Wharton, L.E., N.W. Spencer, and H.G. Mayer, The earth's thermospheric superrotation from Dynamic Explorer 2, Geophys. Res. Lett., 11, 531-533, 1984.

J.H.A. Sobral, and M.A. Abdu, INPE, Av. dos Astronautas, 1758, Calxa Postal 515, 12201 São José dos Campos, São Paulo, Braz1l.

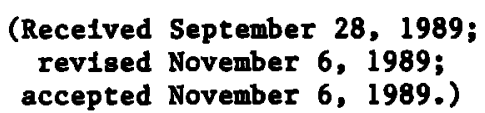

(Recelved September 28, 1989; accepted November 6, 1989.) 